called the public sector. The government has responded indignantly, by saying that this other dismal future has not yet been decreed. But the coincidence of apprehension among the universities and the polytechnics should be an opportunity for the government to weld the two sectors together.

But will there be the students to fill all these institutions? Over the past five years, the British government has fought a running battle of words with British academic institutions over the likely demand for higher education in the years ahead. Government officials have over-anticipated the point at which the demographic retreat of the 1960 s would make itself apparent in reduced demand for higher education, and have consistently been beaten in the argument. Now the official word is that the decline of demand will not arrive until 1990, still just beyond the planning horizon. But there is a sense in which this argument is irrelevant and arcane. The participation rate in British higher education is too low for a state with modern pretensions, while there is an urgent need that Britain should follow most other modern states in providing a four-year education for a greater proportion of its young people, partly for its own sake but crucially so as to allow the cramping specialization of the British high-school curriculum to be decoupled from young people's fateful choice of careers. And then there is the unmet (and, by taxation, repressed) demand for post-experience education.

Where will all this lead? Nowhere, if everybody does nothing. Almost nowhere if only some are prepared to recognize the present opportunity for what it is. But there is just a chance that the coincidence of the latest threat of crisis in British higher education and the prospect that there is electoral advantage to be won will create a sufficient sense of the importance of the occasion to suggest that the time has come radically to modernize an outdated system. That is the best and the only hope.

\section{Insect pests rampant}

\section{Techniques for managing resistance to pesticides have become essential in the United States.}

CHARLES Darwin would readily have understood why the proportion of US crops lost to insects has increased from about 7 per cent in the 1940s to about 13 per cent today. The underlying cause of this alarming development is the repeated use of insecticides (of which the vast majority fall into just four basic chemical types), which has led by means of simple natural selection to the evolution of resistant strains of many of the most important pests. Commercial insect pests have now evolved resistance to all major classes of insecticides, including the most recent addition to the insecticide armoury, the synthetic pyrethroids, and the problem is undoubtedly going to get worse before it gets better. The usual response of the farmer when a resistant strain emerges is to switch to another pesticide, which is fine (although it may be expensive) as long as there are other materials still available. But the cost to the United States of the extra pesticide treatments made necessary by resistance, together with related crop losses, has been estimated to be at least $\$ 150$ million a year and could be much higher. There has been at least one instance where an insect pest became resistant to all applicable pesticides - which put an end to cotton-growing in much of northern Mexico. And the problem is not restricted to insects; other types of pests have also evolved resistance to the principal components of the chemical armoury.

Yet now there is some reason to fear that the renewal of the chemical armoury may have become more difficult. There are indications that the high cost of registering a pesticide with the Environmental Protection Agency (EPA) together with the poor outlook for product lifetime is deterring some manufacturers from developing new products. To be sure, manufacturers have made some efforts to provide farmers with fertilizer schedules that delay the emergence of resistance; it is after all in their interest as well as that of the farmers that products devel- oped and nursed through expensive federal safety testing should retain their usefulness (and profitability) as long as possible. But understanding of the evolution of resistance, despite its economic importance, is still insufficient to allow anything more precise than educated guesses about the consequences of different stategies for the management of resistance.

This is one reason why there is an urgent need for more research. As existing products are withdrawn from the market because of safety fears or resistance, there will be an urgent need for chemicals aimed at new biochemical targets that avoid the dangers posed by cross-resistance to related agents. Who will pay? Industry is wary of such a basic research approach, for understandable reasons: it is inherently risky. Far safer simply to screen and optimize for the short-term biological effectiveness of derivatives of useful known compounds. The US Department of Agriculture, however, does have within its mandate the conduct of fundamental research that could lead to new pesticides, but so far has failed to do very much that is worthwhile. Instead, by means of their responses to research grant proposals, the National Science Foundation and the National Institutes of Health have shouldered most of the burden. The Department of Agriculture should take notice that this is an area of research that has clear potential for long-term economic benefit, but in which there is much basic science still to be learned. If ever there was a case for federal funding of basic research, this is it.

The regulators also need to be more diligent. The US Environmental Protection Agency (EPA) has formal responsibility for the safety and efficacy of pesticides, and has the authority to consider likely problems such as resistance when making licensing decisions. A recent study by the US National Research Council has come down against any formal extension of EPA's regulatory authority (Pesticide Resistance: Strategies and Tactics for Management) but at the same time has revealed how much more there is that EPA could be doing now to encourage responsible pesticide use. During President Reagan's first term of office, the troubles at EPA caused by the politicking of adminstrator Anne Burford left it with little time to worry about the environment outside Washington, and even today the division of EPA responsible for strategies for resistance - the integrated pest management division - is hamstrung by a nonexistent extramural research budget that limits EPA's activities to those for which financial support can be found elsewhere. But even if EPA had the resources to do a credible job of collating information on pesticide resistance and issuing appropriate advice, the bulk of the much-needed applied research into the development of resistance (as opposed to basic research into biochemical mechanisms) would fall on industry. This is as it should be; industry will be the clear benefactor, and is better placed to do the job than government. The effort might even yield pesticides free from the problem of resistance.

At the same time, industry is right to be fearful of Congress giving EPA more statutory responsibility to manage pesticide resistance, at least until the power it already has is used effectively. All relevant experience supports the idea that local and informal decision-making, together with voluntary codes of conduct, are more likely to produce effective management schemes than the heavy hand of statute. One obvious need is that there should be coordinating recommendations on use of different chemicals over long time-periods. Antitrust laws that make companies shy of formulating anti-resistance plans with their competitors are only one example of the practical obstacles that have limited resistance management. While "integrated pest management" schemes introduced over the past decade have undoubtedly helped to delay some instances of resistance, it is equally clear that the scale and nature of the problem requires that industry should be given extra encouragement to develop more effective programmes. Cooperation with state and federal agencies is also needed. In the long run, this may be the only way in which to ensure that better products are eventually produced, and that better use is made of them. 